\title{
Defining Recovery from an Eating Disorder: Conceptualization, Validation, and Examination of Psychosocial Functioning and Psychiatric Comorbidity
}

\author{
Anna M. Bardone-Cone ${ }^{a,}{ }^{\star}$, Megan B. Harney ${ }^{a}$, Christine R. Maldonado ${ }^{b}$, Melissa A. \\ Lawson ${ }^{\mathrm{C}}$, D. Paul Robinson ${ }^{\mathrm{C}}$, Roma Smith ${ }^{\mathrm{C}}$, and Aneesh Tosh ${ }^{\mathrm{C}}$ \\ a Department of Psychology, University of North Carolina at Chapel Hill, Chapel Hill, NC USA \\ b Department of Psychological Sciences, University of Missouri, Columbia, MO, USA \\ c University of Missouri School of Medicine, Columbia, MO, USA
}

\begin{abstract}
Conceptually, eating disorder recovery should include physical, behavioral, and psychological components, but such a comprehensive approach has not been consistently employed. Guided by theory and recent recovery research, we identified a "fully recovered" group $(n=20)$ based on physical (body mass index), behavioral (absence of eating disorder behaviors), and psychological (Eating Disorder Examination-Questionnaire) indices, and compared them with groups of partially recovered $(n=15)$, active eating disorder $(n=53)$, and healthy controls $(n=67)$. The fully recovered group was indistinguishable from controls on all eating disorder-related measures used, while the partially recovered group was less disordered than the active eating disorder group on some measures, but not on body image. Regarding psychosocial functioning, both the fully and partially recovered groups had psychosocial functioning similar to the controls, but there was a pattern of more of the partially recovered group reporting eating disorder aspects interfering with functioning. Regarding other psychopathology, the fully recovered group was no more likely than the controls to experience current Axis I pathology, but they did have elevated rates of current anxiety disorder. Results suggest that a stringent definition of recovery from an eating disorder is meaningful. Clinical implications and future directions regarding defining eating disorder recovery are discussed.
\end{abstract}

\section{Keywords}

Eating disorders; Recovery; Psychosocial functioning; Psychiatric comorbidity

\section{Introduction}

Can an individual who has had an eating disorder every truly recover? To begin to answer that question, we need to have a clear sense of what "true recovery" looks like, yet this is precisely what the field is lacking. Researchers repeatedly bemoan the lack of consensus regarding what constitutes recovery from an eating disorder (e.g., Herzog, Sacks, Keller, Lavori, von Ranson,

(C) 2009 Elsevier Ltd. All rights reserved.

* Corresponding author. Tel.: 1919962 5989; fax: 1919962 2537. bardonecone@ unc.edu (A.M. Bardone-Cone)..

Publisher's Disclaimer: This is a PDF file of an unedited manuscript that has been accepted for publication. As a service to our customers we are providing this early version of the manuscript. The manuscript will undergo copyediting, typesetting, and review of the resulting proof before it is published in its final citable form. Please note that during the production process errors may be discovered which could affect the content, and all legal disclaimers that apply to the journal pertain. 
\& Gray, 1993; Quadflieg \& Fichter, 2003; Steinhausen, 2002; Walsh, 2008). Adopting a consensus definition of recovery is necessary for comparison of findings as well as for the combination of data across studies, with this point being made in both the eating disorder literature (Walsh, 2008) and the depression literature (Frank, 2005). Ideally, agreed-upon provisional criteria would be set forth and then subjected to empirical validation by various research groups so as to permit data-drive refinements. In this paper we propose a theory of eating disorder recovery, along with an operationalization of full recovery which we then seek to validate. We also examine how groups categorized by full recovery and partial recovery compare with active eating disorder cases and healthy controls in important non-eating disorder domains: psychosocial functioning and psychiatric comorbidity.

\subsection{Review of Approaches to Defining Eating Disorder Recovery}

A variety of issues come to bear in determining how to define eating disorder recovery, including what should be included and for how long eating disordered behavior should be absent. Regarding inclusion criteria, the eating disorder field has seen an evolution from a focus on physical criteria such as weight and menses (e.g., Morgan-Russell criteria; Morgan \& Russell, 1975) to the addition of behavioral indices of recovery such as absence of binge eating, compensatory behaviors, and restrictive eating (e.g., Bulik, Sullivan, Fear, \& Pickering, 2000; Field, Herzog, Keller, West, Nussbaum, \& Colditz, 1997; Matsunaga, Kaye, McConaha, Plotnicov, Pollice, \& Rao, 2000; Strober, Freeman, \& Morrell, 1997) to the inclusion of psychological aspects such as body image concerns and fear of weight gain (e.g., Couturier \& Lock, 2006a; Bachner-Melman, Zohar, \& Ebstein, 2006; Strober et al., 1997). However, incorporating physical, behavioral, and psychological indices into a definition of recovery is still far from the norm and is not being done in any standardized way across studies.

Most often missing from "recovery" is the psychological component of eating disorders, especially how individuals think about their bodies, food, and eating. Not assessing for psychological recovery may produce a "pseudorecovery" state (Keski-Rahkonen \& Tozzi, 2005) where individuals are "walking the walk" but internally "talking" the same eating disordered talk. The presence of lingering eating disorder attitudes is not trivial, since elevated anorexic attitudes and residual concerns about weight and shape predict relapse (Carter, Blackmore, Sutandar-Pinnock, \& Woodside, 2004; Channon and DeSilva, 1985; Federici \& Kaplan, 2008). Some researchers note that the findings that cognitive features of disordered eating, including body image disturbance, predict relapse may reflect a deficiency in how recovery from an eating disorder is defined (Keel, Dorer, Franko, Jackson, \& Herzog, 2005). Interestingly, Cogley and Keel (2003) found that when influence of weight/shape was included as a recovery criterion, the fully recovered group had less body dissatisfaction, less negative affect, and better social adjustment than a partially recovered group and looked similar to healthy controls on these measures. Similarly, Bachner-Melman et al. (2006) reported that only individuals who were recovered cognitively in addition to behaviorally were comparable to controls on measures of body dissatisfaction, disordered eating, drive for thinness, and endorsement of the thin ideal. Furthermore, women who identified as recovered highlighted accepting one's appearance and not obsessing about weight (i.e., psychological aspects) as representing full recovery to them (Noordenbos \& Seubring, 2006).

In addition to which criteria should be included is the issue of how long eating disorder behaviors should be absent to constitute recovery. Studies of eating disorder recovery have used various durations, typically specifying from eight consecutive weeks to one year without eating disorder behaviors (Bachner-Melman et al 2006; Daley, Jimerson, Heatherton, Metzger, \& Wolfe, 2008; Herzog et al., 1999; Kordy et al., 2002). Kordy et al. (2002) provide some support for absence of anorexic symptoms for two months being an adequate duration for stable remission from anorexia nervosa, but suggest that four months should be the duration of the 
absence of bulimic symptoms for bulimia nervosa. Other work argues for a one-year period without eating disorder behaviors, based on the literature indicating that risk for relapse is greatest within one year post-treatment or post-recovery (Herzog, Schellberg, \& Deter, 1997; Strober et al., 1997). Given the consistent finding that psychological recovery follows behavioral recovery (Fichter, Quadflieg, \& Hedlund, 2006; Strober et al., 1997), a shorter duration of behavioral recovery is arguably acceptable when combined with a valid measure of psychological recovery. ${ }^{1}$

\subsection{Operationalization and Theory of Eating Disorder Recovery}

We propose that full recovery is achieved when individuals with a history of an eating disorder appear indistinguishable from healthy controls (defined as having no history of an eating disorder) on indices reflecting behavioral and psychological aspects of eating disorders. We have operationalized our definition of full recovery as follows: 1) no longer meeting diagnostic criteria for an eating disorder (anorexia nervosa-AN, bulimia nervosa-BN, or eating disorder not otherwise specified-EDNOS); 2) no binge eating, purging (e.g., vomiting, laxative use), or fasting in the past three months; 3 ) a body mass index of at least $18.5 \mathrm{~kg} / \mathrm{m}^{2}$ (a BMI of 18.5-24.9 is considered normal by the World Health Organization; Bjorntorp, 2002); and 4) scores within $1 S D$ of age-matched community norms on all the subscales of the Eating Disorder Examination-Questionnaire (EDE-Q; Fairburn \& Beglin, 1994): Restraint, Eating Concern, Weight Concern, and Shape Concern. In contrast, we refer to "partial recovery" as meeting all of the above criteria except the EDE-Q thresholds; that is, meeting physical and behavioral criteria, but not psychological criteria, for recovery.

The combination of both a weight threshold and psychological indices (i.e., EDE-Q) is in line with work by Couturier and Lock (2006a) who suggest that this combination yields a more accurate and comprehensive picture of recovery. Unlike Couturier and Lock (2006a), we use the EDE-Q rather than the Eating Disorder Examination (EDE; Fairburn \& Cooper, 1993). Since the EDE-Q is directly derived from the EDE (Fairburn \& Beglin, 1994), is wellestablished with psychometric support (Fairburn \& Beglin, 1994; Grilo, Masheb, \& Wilson, 2001; Luce \& Crowther, 1999), has normative data from a large community sample (Mond, Hay, Rodgers, \& Owen, 2006), and is easier to administer and more likely to be used by clinics than the EDE, it is a valuable assessment tool to implement in the service of identifying full recovery.

It could be argued that this definition of recovery is too ambitious. However, we believe there is value in setting the bar high for full recovery for several reasons. First, once attained, this stage of recovery should represent individuals who are at minimal risk of relapse and permit the assessment of predictors of this level of recovery. Second, by identifying this group, we provide images of recovery that exist but that individuals with eating disorders, their families, and their health care providers may not think are possible. Third, a more stringent definition of recovery offers greater conceptual clarity which is important in fine-tuning interventions.

Our proposed conceptualization of full recovery is applicable regardless of the past eating disorder diagnosis. That is, we argue that a meaningful and parsimonious way to define recovery is to make it applicable to those recovering from AN, BN, or EDNOS. This approach is practical given that migration from one type or subtype of eating disorder to another is

\footnotetext{
${ }^{1}$ Other sources of variability in defining eating disorder recovery include choice of weight threshold, with studies using BMIs of 18 , 18.5, and 19 as lower bounds for recovery (Bachner-Melman et al., 2006; Bachner-Melman, Zohar, Ebstein, \& Bachar, 2007; Bosanac et al., 2007) and whether or not a return to normal menstrual functioning should be required for recovery. Regarding weight, Couturier and Lock (2006b) argue that a lower weight threshold is acceptable if paired with more stringent psychological criteria. Regarding the return of menses, evidence suggests that amenorrhea may not have diagnostic significance (Roberto et al., 2008) and that the return of normal menstrual functioning is of limited use as a recovery criterion since it does not apply to males, premenstrual girls, or females using oral contraceptives.
} 
common (Tozzi et al. 2005) and given that EDNOS is a large and heterogeneous group (Eddy, Doyle, Hoste, Herzog, \& le Grange, 2008).

\subsection{Psychosocial Functioning and Axis I Psychopathology}

We believe it is important to examine psychosocial functioning and other psychopathology to further understand the lives of individuals recovering from eating disorders, but do not include these domains in the definition of eating disorder recovery. This approach is similar to that applied by researchers defining recovery for major depressive disorder (Frank et al., 1991; Rush et al., 2006); for example, Rush et al. (2006) argue that daily functioning should not be included in defining recovery from depression since this is affected both by the disorder of interest and any number of other factors. Below we summarize psychosocial and Axis I disorder findings, but note that they are generally constrained by the different definitions of recovery and, notably, by the absence of clear psychological recovery from eating disorders including healthier attitudes toward the body, food, and eating.

Research examining psychosocial outcomes across stages of recovery has typically focused on overall functioning ratings or questions about status (e.g., marriage, employment) with less attention to qualitative psychosocial adjustment in different domains (Pike, 1998). Studies have generally found overall improvement in psychosocial functioning among recovered individuals (Halvorsen, Andersen, \& Heyerdahl, 2004; Keel, Mitchell, Miller, Davis, \& Crow, 2000; Keski-Rahkonen et al., 2009; Lowe, Zipfel, Buchholz, Dupont, Reas, \& Herzog, 2001). However, others found that even among those who appeared recovered from an eating disorder there was impaired social functioning as indicated by low social support, low social network size, and low life satisfaction (Striegel-Moore, Seeley, \& Lewinsohn, 2003). In another study, although individuals in remission from $\mathrm{BN}$ reported similar overall social adjustment as did a community sample, impairments in relationships appeared to persist (Keel, Mitchell, Miller, et al., 2000).

Researchers interested in non-eating disorder pathology among those with past but not current eating disorders have found significant depressive and anxiety symptoms in weight-recovered AN groups (Bosanac et al., 2007; Pollice, Kaye, Greeno, \& Weltzin, 1997). Wagner et al. (2006) reported that women recovered from an eating disorder had similar rates of Axis I disorders (mood, anxiety, substance use) as women with a current BN diagnosis. However, Herpertz-Dahlmann and colleagues (2001) found that long-term recovered individuals were no more likely to have Axis I disorders than healthy controls, and Halvorsen et al. (2004) found that those with good outcomes from AN were more likely to be free of Axis I pathology. In one study that made a distinction between levels of recovery, there was a general pattern for the group with the good outcome having fewer cases of mood and anxiety disorders compared to the group with the intermediate outcome which, in turn, had fewer cases than the active eating disorder group (Lowe et al., 2001).

\subsection{The Current Study}

In sum, in the current study we operationalized a way of defining eating disorder recovery that is based on theory and prior research and that is parsimonious and easily applied. We tested the validity of this definition by examining how the fully recovered group compared to healthy controls, a partially recovered eating disorder group, and an active eating disorder group using eating disorder assessments not used in defining recovery. We hypothesized that the fully recovered group would be indistinguishable from the healthy controls on these measures, and that the partially recovered group would fall some place between the fully recovered group and the active eating disorder group on eating disorder-related pathology. We also examined how these groups compared on current psychosocial functioning and non-eating disorder Axis I psychopathology, hypothesizing that the fully recovered group would have better psychosocial 
functioning and less psychopathology than the partially recovered and active eating disorder groups.

\section{Method}

\subsection{Participants and Recruitment}

Attempts were made to contact all current and former female eating disorder patients (ages 16 and older) seen at the University of Missouri Pediatric and Adolescent Specialty Clinic ( $N$ $=273$ ) between 1996 and 2007, the year of data collection. This clinic is a primary care and referral clinic specializing in the care of children and adolescents (ages 10-25 years) that has physicians with expertise in eating disorders. Of the 273 eating disorder patients, $96(35.2 \%)$ were successfully contacted and recruited. Fifty-five $(20.1 \%)$ of the 273 were contacted but did not participate due to other time commitments or lack of interest. Of the remaining patients, four $(1.5 \%)$ were deceased and 118 patients $(43.2 \%)$ could not be contacted due to absent or incorrect mailing addresses or inability to make phone contact. These rates are fairly comparable to those of other studies doing a follow-up of eating disorder patients over a range of about 10 years (Reas, Williamson, Martin, \& Zucker, 2000; Yackobovitch-Gavan et al., 2009). In sum, of the 151 eating disorder patients we were able to contact, $63.6 \%$ participated. Healthy controls were recruited from two sources: the clinic from which the eating disorder patients were recruited $(n=17)$ and the university campus $(n=50)$. Eligible controls were females ages 16 and older with no current or past eating disorder symptoms.

For all participants recruited from the clinic (former and current eating disorder patients and healthy controls), current contact information was sought via patient records, public records such as whitepages.com, court records, and marriage records, and paid tracking searches. Eligible participants were mailed a cover letter that described the study and included the lead researcher's phone number for finding out more information or expressing interest. Up to two mailings were sent out and if there was no response at that point, then attempts were made to contact the eligible participant via phone to describe the study and solicit participation. Recruitment for the healthy controls outside of the clinic occurred through fliers and introductory psychology courses. Those who responded to the flier, which noted inclusion criteria of no current or past eating disorder symptoms, called the lead researcher at which point the inclusion criteria were reiterated and the study was described. Those who were recruited from introductory psychology classes were contacted via phone if they met inclusion criteria based on screening measures administered at the start of the semester.

\subsection{Study Procedures}

After providing written consent, all participants first completed a set of questionnaires and then, on a separate date, an interview. (For participants under the age of 18, we obtained written assent from the minor and written consent from a parent.) For the majority of the participants, the time between questionnaires and interview was within one week. Most participants completed the questionnaires $(71.2 \%)$ and interview $(82.9 \%)$ in person. Those who lived too far away to travel to the study site completed the questionnaires via mail and did a phone interview. Interviews were privately conducted by one of three extensively trained individuals who participated in over 50 hours of training videos, role plays, and discussions about interviewing. Participants were provided financial remuneration after completing the interview, except for the controls from psychology classes who received course credit. Current and former eating disorder patients received $\$ 50$ and healthy controls recruited from outside psychology classes received $\$ 35$, with the difference reflecting differences in time in the study. (The eating disorder groups' interviews were on average 1.5 hours longer than controls' interviews due to greater complexity in their diagnostic interviews and additional interview 
components such as motivation for recovery.) All aspects of this study were approved by the university's institutional review board.

\subsection{Measures Used for Defining Eating Disorder Status Groups}

2.3.1. Structured Clinical Interview for DSM-IV, Patient Edition-(SCID; First, Spitzer, Gibbon, \& Williams, 1995). The SCID was administered to determine lifetime and current eating disorder diagnoses (AN, BN, EDNOS). ${ }^{2}$ EDNOS cases were those that met the SCID's guidelines for EDNOS (e.g., subthreshold AN, subthreshold BN, regular use of inappropriate compensatory behaviors, and binge eating disorder). A random subset (about $5 \%$ ) of the principal investigator's (AB-C) audiotaped interviews were rated by the other two interviewers to assess inter-rater reliability, yielding absolute agreement for current $\mathrm{AN}, \mathrm{BN}$, and EDNOS.

\subsubsection{Eating Disorders Longitudinal Interval Follow-up Evaluation interview-} (LIFE EAT II; Herzog et al., 1993). We used portions of the LIFE EAT II asking about the presence of binge eating, vomiting, laxative use, and fasting over the past three months.

2.3.3. Eating Disorder Examination-Questionnaire-(EDE-Q; Fairburn \& Beglin, 1994). The EDE-Q assesses disordered eating thoughts and behaviors over the past four weeks, yielding four subscales: Restraint (attempts to restrict food intake), Eating Concern (feeling guilty and concerned about eating), Weight Concern (dissatisfaction with and overvaluation of weight), and Shape Concern (dissatisfaction with and overvaluation of shape). The EDE-Q is one of the most commonly used measures of disordered eating attitudes and behaviors in clinical and community populations (Anderson \& Williamson, 2002) and its subscales have good internal consistency (alphas of .78-.93; Luce \& Crowther, 1999) and convergent validity (Fairburn \& Beglin, 1994; Grilo et al., 2001). This questionnaire is derived from the EDE interview (Fairburn \& Cooper, 1993), which was used in prior work in defining eating disorder recovery (Couturier \& Lock, 2006a). In the current study, coefficient alphas were $\geq .85$ for all subscales.

2.3.4. Body mass index-Weight and height were measured after the interview and used to compute body mass index (BMI). For those who completed the interview over the phone, we used self-reported height and weight in the BMI computations.

\subsection{Measures Used for Demonstrating Validity of the Full Recovery Group}

The validity of our operationalization of full eating disorder recovery was tested using both well-established measures and items developed for this study, all administered as questionnaires prior to the interview. The published measures, described in Table 1, assessed disordered eating behaviors and attitudes with special emphasis on psychological aspects including eating disorder cognitions and body image. All of these measures have strong psychometric support, are commonly used in eating disorder research, and had excellent reliability in the current sample (all coefficient alphas $\geq .90$ ).

Additionally, we assessed obsessionality related to eating disorders in two ways. Participants reported on how much time they typically spent thinking about their weight, part of their body, and food/eating, using a 5-point scale from no time or almost no time to almost all of the time or all the time. Coefficient alpha for this 3-item measure was .83, and the mean score was used in analyses. Participants also reported how difficult it would be to stop thinking about each

\footnotetext{
${ }^{2} \mathrm{~A}$ diagnosis of AN was given whether or not the amenorrhea criterion was met. Other researchers have expressed concerns about requiring this criterion (Roberto et al., 2008) and have not required the presence of amenorrhea for a diagnosis of AN (Kaye et al., 2004).
} 
topic (weight, body, food/eating), with response options of 1=extremely easy to 5=extremely difficult. Coefficient alpha for this 3-item measure was .91, and the mean score was used in analyses. We also asked about strength of urges to engage in the following behaviors: binge eating, vomiting, laxative use, and food restriction, using a 7-point scale from no urges at all to extremely strong urges in reference to the past week. Coefficient alpha for this 4-item measure was .79, and the mean score was used in analyses.

\subsection{Measures Related to Psychosocial Functioning}

All of the items described in this section were part of the interview, collected after the completion of the SCID. Although interviewers were aware of participants' current eating disorder diagnosis during the psychosocial assessment part of the interview, they were unaware of the additional data used to determine recovery group status, namely EDE-Q scores.

To assess domain-specific functioning in the areas of work, school, and relationships (mother, father, romantic partner, friends), we used questions from the psychosocial section of the LIFE EAT II (Herzog et al., 1993). Based on participants' descriptions of their functioning and responses to probes, interviewers rated their functioning for each of the past three months. For work and school, the ratings ranged from 1=no impairment and functioned at a high level to $6=$ did not work or attend school due to psychopathology. For relationships, the ratings ranged from $1=$ very good to $5=$ very poor. The average functioning across the three months was used in analyses, and inter-rater reliability for these mean ratings ranged from $r=.89$ to $r=1.00$ in the subset of interviews examined. Participants for whom the domain did not apply (e.g., no romantic partner in the past three months) were excluded from analyses involving functioning in that domain. All participants other than the healthy controls were also asked for each domain whether eating disorder aspects ever interfered with their functioning in the past three months.

\subsection{Measures Related to Axis I Psychopathology}

The SCID (First et al., 1995) was used to determine current diagnoses of: mood disorders (major depressive disorder, depressive disorder not otherwise specified, bipolar I, bipolar II), anxiety disorders (panic disorder, agoraphobia, social phobia, specific phobia, obsessive compulsive disorder, generalized anxiety disorder, anxiety disorder not otherwise specified), and substance use disorders (alcohol abuse or dependence and substance abuse or dependence). Based on the subset of interviews, there was absolute agreement for current mood disorder and substance disorder. For current anxiety disorder, $\kappa$ ranged from moderate to excellent: .50 to 1.00 .

\section{Results}

\subsection{Creating Eating Disorder Status Groups}

Participants were categorized into four eating disorder status groups in the following way. Healthy controls $(n=67)$ had no history of an eating disorder, and active eating disorder cases $(n=53)$ had a current eating disorder diagnosis (AN, BN, or EDNOS). Individuals who had a history of an eating disorder (AN, BN, or EDNOS), but did not currently meet eating disorder criteria were further examined to determine the extent of their recovery, following the general guidelines recommended by Couturier and Lock (2006a). The fully recovered group $(n=20)$ comprised women without a current eating disorder who had a BMI of at least 18.5, reported no binge eating, purging, or fasting in the prior three months, and scored within $1 S D$ of agematched community norms on each of the EDE-Q subscales. The partially recovered group $(n=15)$ included women without a current eating disorder who were recovered physically (BMI $\geq 18.5$ ) and behaviorally (no binge eating, purging, or fasting in the past three months) but not psychologically (at least one EDE-Q subscale greater than $1 S D$ of age-matched norms). ${ }^{3}$ The norms used for determining fully and partially recovered status were the age-banded norms 
reported by Mond et al. (2006), so that for a given eating disorder patient, her EDE-Q scores were compared to those of women of a similar age. We chose to use $1 S D$ from norms rather than $2 S D$ from norms because $2 S D$ from norms on the EDE-Q subscales often included scores of 4 or higher, which are considered clinically significant (Mond et al., 2006), and because we wanted to set a high bar for recovery.

\subsection{Descriptive Statistics and Attrition Analyses}

Table 2 includes descriptive statistics of the four groups in terms of age, ethnicity, and socioeconomic status. The groups did not differ in terms of ethnicity and socio-economic status, but did differ in age $(F(3,151)=15.44, p<.001)$, with healthy controls significantly younger than the eating disorder groups. Controlling for age did not change the pattern of significance, so results without age as a covariate are presented for parsimony. The fully recovered, partially recovered, and active eating disorder groups did not differ in their pattern of lifetime eating disorder diagnoses (e.g., no significant differences in the percentage with a lifetime diagnosis of $\mathrm{AN}$ ), the number of years since the emergence of the eating disorder symptoms, or age or BMI at start of treatment (all $p$ 's > .37). Of the active eating disorder group, $17.0 \%$ currently had $\mathrm{AN}, 5.7 \%$ had BN, and 77.4\% had EDNOS.

In order to examine whether the individuals who participated differed from those who did not, we used clinic chart data to make comparisons. The participants were not significantly different from the non-participants (those with whom contact was never made or who declined to participate but agreed to let us use limited chart information) in terms of current age, age at first clinic visit, BMI at first clinic visit, eating disorder diagnoses, and number of years since last clinic visit. These findings provide confidence that, at least on these measures, study participants were representative of the larger eating disorder patient population at this clinic.

\subsection{Validity of Recovery Groups}

Table 3 displays information from analysis of variance (ANOVA) analyses where eating disorder status was the independent variable and the disordered eating measure was the dependent variable. Significant effects were followed up with Tukey HSD tests for pair-wise comparisons. The fully recovered group was consistently significantly less disordered than both the partially recovered and active eating disorder groups. It is notable that the fully recovered group and healthy controls did not differ significantly on any of the eating disorder assessments; furthermore, inspection of the means for these two groups revealed remarkably similar scores. In contrast, the partially recovered group was significantly less disordered than the active group on only two measures: the EAT-26 and urges to binge, vomit, use laxatives, and restrict. Interestingly, the partially recovered group did not differ from the active eating disorder group on any of the body image-related constructs, for example, appearance schemas, body shame, and thin-ideal internalization. As additional evidence supporting the current eating disorder status distinctions, the mean EAT-26 score of the active eating disorder group was above the clinical cut-off of 20 , the mean for the partially recovered group was below but close to 20 (mean of about 17), and the fully recovered group and healthy controls had similarly low scores (about 5) well below the clinical cut-off.

\footnotetext{
${ }^{3}$ Eight of the 96 current and former eating disorder patients did not meet criteria for a current eating disorder or either definition of recovery (i.e., partial recovery of physical and behavioral recovery, but not psychological recovery, or full recovery of physical, behavioral, and psychological recovery). These were primarily individuals who had reported some (though minimal) binge eating or purging, typically once or twice in the past three months. We excluded these individuals from analyses in order to produce "cleaner" recovery groups and in order to include a recovery group more typical of what is seen in the literature (i.e., physical and behavioral recovery). However, when analyses were run including these eight individuals in the "partial recovery" group, the same pattern of results emerged as presented in this work using the stricter definition of partial recovery.
} 


\subsection{Psychosocial Functioning}

Table 4 contains findings related to functioning in the specific domains in the past three months based on ANOVAs, with significant effects followed up with Tukey HSD tests for pair-wise comparisons. There were group differences in work functioning, with healthy controls, fully recovered, and partially recovered groups functioning better than the active eating disorder group. Healthy controls and the fully recovered group also reported having better relationships with their fathers and with their friends than the active eating disorder group. There was a less striking group difference in terms of functioning in romantic relationships, and no group differences related to relationships with mothers.

Table 5 provides descriptive information regarding the percentiles endorsing that eating disorder aspects interfered with their lives in the past three months. The general pattern was for the fully recovered group to have the fewest reporting this interference, followed by the partially recovered group, and then the active eating disorder group. When groups were compared on whether they reported eating disorder aspects interfering with any psychosocial domain in the past three months, $11.8 \%(n=2)$ of the fully recovered group, $40.0 \%(n=6)$ of the partially recovered group, and $72.9 \%(n=35)$ of the active eating disorder group reported such interference, $\chi^{2}(2, N=80)=20.29, p<.001 .{ }^{4}$ As another way to consider group differences in psychosocial functioning, a logistic regression was run with the binary outcome of presence/ absence of any psychosocial interference as the dependent variable. In comparison to the active eating disorder group, the fully recovered group was significantly less likely to report eating disorder aspects interfering in their lives (odd ratio $(\mathrm{OR})=.05$, confidence interval $(\mathrm{CI})=.01$ $25, p<.001)$, as was the partially recovered group $(\mathrm{OR}=.25, \mathrm{CI}=.07-.83, p=.024)$.

\subsection{Axis I Psychopathology}

Table 6 displays the percentages of each group with a current mood disorder, anxiety disorder, substance use disorder, and any non-eating disorder Axis I disorder. For mood disorders (primarily major depressive disorder), healthy controls and the fully recovered group had similarly low rates of current diagnoses, in contrast to the one-fifth of the partially recovered group and about one-third of the active eating disorder group with mood disorders. For anxiety disorders, it was the fully recovered and partially recovered groups that were more similar, exhibiting higher rates than the healthy controls but lower rates than the active eating disorder group. Groups were similar in terms of substance use disorders, which had low base rates. Finally, when compared in terms of presence of any current non-eating disorder diagnosis, there was a stairstep progression across the groups by level of eating disorder severity. Based on a logistic regression analysis with the binary outcome of presence/absence of any non-eating disorder Axis I disorder as the dependent variable, the partially recovered group was about 3 times more likely to have a psychological disorder than the healthy controls $(\mathrm{OR}=3.31$, $\mathrm{CI}=1.03-10.70, p=.045$ ), while the active eating disorder group was about 7 times more likely $(\mathrm{OR}=7.35, \mathrm{CI}=3.20-16.86, p<.001)$. The fully recovered group did not differ from the healthy controls in their likelihood of having a non-eating disorder Axis I disorder $(\mathrm{OR}=1.89, \mathrm{CI}=$. $60-5.94, p=.274)$.

\section{Discussion}

The current findings provide evidence that full recovery from an eating disorder is possible, including the attainment of normal attitudes toward food and the body. This suggests that prior findings that residual symptoms often persist in those recovered from an eating disorder may

\footnotetext{
${ }^{4}$ Since such a small subset of the eating disorder groups (active, partially recovered fully recovered) reported student activity in the past three months, we only included data about student functioning in the composite of experiencing interference from eating disorder aspects in any psychosocial domain (i.e., work, school, relationships).
} 
be an artifact of an incomplete definition of recovery. We found that those who no longer meet criteria for an eating disorder, who have not engaged in bingeing, purging, or fasting in the past three months, who have a BMI of at least 18.5 , and who score within $1 S D$ of age-matched community norms on all the EDE-Q subscales appear to have attained full recovery, and were indistinguishable from healthy controls on a wide range of disordered eating measures that focused on cognitions related to body image, eating, and food. In contrast, a partially recovered eating disorder group that was recovered physically and behaviorally, but not psychologically, was similar to an active eating disorder group, in terms of disordered eating cognitions. It is noteworthy that the partially recovered and active eating disorder groups did not differ on body image-related measures, but fully recovered and active eating disorder groups did. This finding is consistent with prior work where only individuals who were both cognitively and behaviorally recovered looked comparable to controls in terms of body dissatisfaction and endorsement of the thin ideal (Bachner-Melman et al., 2006). It appears as though body image disturbances may be key to distinguishing between partially and fully recovered individuals, and that a healthier relationship with one's body may be the final hurdle in recovery.

In terms of functioning in specific psychosocial domains, partially recovered, fully recovered, and healthy control groups functioned at comparable levels. These findings provide some optimism that even if a partially recovered individual maintains eating disorder attitudes similar to her active eating disorder peers, she may function similarly to those with no eating pathology in terms of psychosocial adjustment. There was some evidence that only healthy controls and fully recovered individuals functioned better than active eating disorder individuals in some relationships (with father, friends).

To some degree, it was surprising that $12 \%$ of the fully recovered group reported that aspects of the eating disorder had interfered with psychosocial functioning in the past three months. However, this percentage is markedly less than the $40 \%$ for the partially recovered group and the $73 \%$ for the active eating disorder group. For a minority of the otherwise fully recovered individuals, there may be some scar effects of the eating disorder. It could also be that in some cases the eating disorder interference in relationships was due to others continuing to express concerns that may be unwarranted - for example, a mother pushing her daughter to eat more when the daughter has eaten a reasonable meal and is sated, leading to tension. Of note, participants reported if eating disorder aspects had ever interfered in various domains across the past three months, so individuals for whom this had happened once were grouped with those for whom it had happened frequently. Future research should assess eating disorder interference as a continuous rather than dichotomous variable. Also, future work should incorporate more tailored measures of psychosocial impairment secondary to disordered eating attitudes and behaviors and make use of new quality of life instruments (Bohn, Doll, Cooper, O'Connor, Palmer, \& Fairburn, 2008; Engel, Adair, Las Hayas, \& Abraham, 2009).

In terms of Axis I disorders, there was evidence for the fully recovered group looking both similar to controls (in terms of percentiles with a current mood disorder) and more pathological (in terms of percentiles with a current anxiety disorder). These results fit with existing work suggesting that anxiety disorders tend to precede eating disorders (Kaye, Bulik, Thornton, Barbarich, Masters, \& Price Foundation Collaborative Group, 2004), but depressive disorders are more often a consequence or concomitant of eating disorders (Herpertz-Dahlmann et al., 2001; Wentz, Gillberg, Gillberg, \& Rastam, 2001). Interestingly, the fully and partially recovered groups had similar proportions of individuals with an anxiety disorder (about onethird). It could be that for those who are fully recovered but with a current anxiety disorder, the underlying pathology that may have driven both an eating disorder and an anxiety disorder continues to be expressed, but only in the domain of non-eating disorder related anxiety. Overall, the partially recovered and active eating disorder groups, but not the fully recovered 
group, were significantly more likely to experience current non-eating disorder pathology than healthy controls.

This study contributes to the literature with its theoretical conceptualization and operationalization of eating disorder recovery, along with a validation of this way of defining recovery. Thus, this work follows recommendations in the depression literature related to empirically validating a proposed category of recovery (Frank et al., 1991). It is also one of a limited number of recovery studies assessing non-eating disorder psychopathology and psychosocial functioning, and one of the few focusing on quality of psychosocial functioning rather than status variables. Generalizabiltiy is also a strength; by sampling from a facility other than an eating disorder clinic we were able to study a group with greater variability of severity - our sample included individuals with diagnosable but less severe eating disorders as well as individuals with multiple hospitalizations. Finally, it is a strength that the healthy controls were determined only by absence of a past or current eating disorder, rather than by absence of any past psychopathology which would create "super healthy" controls that are less representative and against which it would be easier to find group differences (Klump et al., 2004).

In terms of limitations, all data were self-report (albeit via a combination of interview and questionnaires) and the sample size was relatively small. We note that we were not able to contact a significant minority of individuals. Some of the particular challenges in locating young women for follow-up, in some cases over 10 years since their last clinic visit, included women who married and changed their last name as well as the now widespread use of mobile phones for which numbers are not recorded in any accessible registry. Of those we were able to contact, the majority did participate and no significant differences were found between participants and non-participants on relevant measures such as eating disorder diagnosis. It is also a limitation that the healthy controls were younger than the other three groups and that the participants were homogenous in terms of demographics. Future work should ensure that comparison groups are age-matched and should include males and greater racial/ethnic diversity for better generalizability. Another limitation is the cross-sectional design, which provides a snapshot of what is a dynamic process. Prospective, longitudinal research is needed to understand movement across eating disorder stages, to better assess the degree of severity during the active phase of an eating disorder that might predict recovery outcome, and to identify who relapses, thus providing further tests of the validity of this definition of full recovery. Finally, it may be argued that lumping together AN, BN, and EDNOS is a limitation, especially given evidence of different temporal patterns of recovery for AN and BN (Von Holle et al., 2008). Others may argue that this is an appropriate approach given eating disorder diagnostic migration (Tozzi et al. 2005) and the common core pathology of overvaluation of weight and shape (Fairburn, 2008). Future research with larger samples will want to examine these groups separately in order to determine if there are differences in predictors of comprehensive recovery for different eating disorder diagnoses.

The finding that full recovery exists is important information for practitioners and eating disorder patients and their families so that they have a sense of what recovery can look like. Given that the fully recovered and partially recovered individuals differed in terms of body shame, appearance schemas, and thin-ideal internalization, these may be fruitful targets of intervention among those on a recovery trajectory. Also, given that individuals fully and partially recovered from eating disorders reported elevated rates of current anxiety disorders and given the biological and genetic underpinnings of eating and anxiety pathology (Kaye et al., 2004), practitioners working with individuals with eating disorders may want to make sure that anxiety symptoms are also a focus of treatment. What needs to occur for full recovery, namely, psychological recovery in addition to physical and behavioral recovery, also has implications in the context of managed care. While future prospective research needs to determine whether those fully recovered are at significantly lower risk for relapse than those 
partially recovered, should this be borne out, then insurance companies should cover services that facilitate comprehensive recovery in order to reduce the revolving door phenomenon of eating disorder relapse. Finally, the findings also have implications for the definition and assessment of full recovery. Using the EDE-Q, BMI, and an assessment of binge eating, purging, and fasting among those with a past, but not current, eating disorder appears to be a logistically practical way to identify meaningful recovery that is cost-effective and efficient time-wise.

In sum, full recovery from an eating disorder appears to be a realistic goal, with future research needed to determine for whom it is a more realistic goal than for others. The inclusion of an explicit psychological piece of recovery is critical for identifying a more meaningfully recovered group that should be at low risk for relapse in what are often seen as chronic disorders. Future research should prospectively follow these recovery groups to provide further validation of the current operationalization of recovery and to identify predictors of trajectories. For example, longitudinal research could elucidate what predicts someone in partial recovery progressing to full recovery, staying in partial recovery, or relapsing. Factors such as coping skills and social support should be examined as potential contributors to full recovery (Bloks et al., 2004). Given the need for researchers to agree on a definition of eating disorder recovery (Walsh, 2008) and the desirability of finding a definition of full recovery that is valid, based on psychometrically strong measures, and easily applied, we propose that the current operationalization is a promising approach that is both meaningful and practical. Thus, rather than arguing that other operationalizations should not be considered, we propose that researchers interested in examining eating disorder outcomes should design their studies to allow them to operationalize recovery as proposed in this paper.

\section{Acknowledgments}

This research was supported in part by the following grants: NIH 1 R03MH074861-01A1; University of Missouri PRIME Grant; and University of Missouri Research Council Grant. We greatly appreciate the time and effort of the study participants in sharing their past and current experiences with us.

\section{References}

Anderson, DA.; Williamson, DA. Outcome measurement in eating disorders. In: IsHak, WW.; Burt, T.; Sederer, LI., editors. Outcome measurement in psychiatry: A critical review. American Psychiatric Press; Washington, DC: 2002. p. 289-301.

Bachner-Melman R, Zohar AH, Ebstein RP. An examination of cognitive versus behavioral components of recovery from anorexia nervosa. Journal of Nervous and Mental Disease 2006;194:697-703. [PubMed: 16971822]

Bachner-Melman R, Zohar AH, Ebstein RP, Bachar E. The relationship between selflessness levels and the severity of anorexia nervosa symptomatology. European Eating Disorders Review 2007;15:213200. [PubMed: 17676691]

Bjorntorp, P. Definition and classification of obesity. In: Fairburn, CG.; Brownell, KD., editors. Eating disorders and obesity. 2nd ed.. Guilford; New York: 2002. p. 377-381.

Bloks H, van Furth EF, Callewaert I, Hoek HW. Coping strategies and recovery in patients with a severe eating disorder. Eating Disorders 2004;12:157-169. [PubMed: 16864314]

Bohn K, Doll HA, Cooper Z, O'Connor M, Palmer RL, Fairburn CG. The measurement of impairment due to eating disorder psychopathology. Behaviour Research and Therapy 2008;46:1105-1110. [PubMed: 18710699]

Bosanac P, Kurlender S, Stojanovska L, Hallam K, Norman T, McGrath C, et al. Neuropsychological study of underweight and "weight-recovered" anorexia nervosa compared with bulimia nervosa and normal controls. International Journal of Eating Disorders 2007;40:613-621. [PubMed: 17607697] 
Bulik CM, Sullivan PF, Fear JL, Pickering A. Outcome of anorexia nervosa: Eating attitudes, personality, and parental bonding. International Journal of Eating Disorders 2000;28:139-147. [PubMed: 10897075]

Carter JC, Blackmore E, Sutandar-Pinnock K, Woodside DB. Relapse in anorexia nervosa: A survival analysis. Psychological Medicine 2004;34:671-679. [PubMed: 15099421]

Cash TF, Melnyk SE, Hrabosky JI. The assessment of body image investment: An extensive revision of the Appearance Schemas Inventory. International Journal of Eating Disorders 2004;35:305-316. [PubMed: 15048946]

Channon S, DeSilva WP. Psychological correlates of weight gain in patients with anorexia nervosa. Journal of Psychiatric Research 1985;19:267-271. [PubMed: 4045744]

Cogley CB, Keel PK. Requiring remission of undue influence of weight and shape on self-evaluation in the definition of recovery for bulimia nervosa. International Journal of Eating Disorders 2003;34:200-210. [PubMed: 12898556]

Couturier J, Lock J. What is recovery in adolescent anorexia nervosa? International Journal of Eating Disorders 2006a;39:550-555. [PubMed: 16791851]

Couturier J, Lock J. What is remission in adolescent anorexia nervosa? A review of various conceptualizations and quantitative analysis. International Journal of Eating Disorders 2006b; 39:175-183. [PubMed: 16485268]

Daley KA, Jimerson DC, Heatherton TF, Metzger ED, Wolfe BE. State self-esteem ratings in women with bulimia nervosa and bulimia nervosa in remission. International Journal of Eating Disorders 2008;41:159-163. [PubMed: 18004722]

Eddy KT, Doyle AC, Hoste RR, Herzog DB, le Grange D. Eating disorder not otherwise specified in adolescents. Journal of the American Academy of Child and Adolescent Psychiatry 2008;47:156164. [PubMed: 18176335]

Engel SG, Adair CE, Las Hayas C, Abraham S. Health-related quality of life and eating disorders: A review and update. International Journal of Eating Disorders 2009;42:179-187. [PubMed: 18949768]

Fairburn, CG. Eating disorders: The transdiagnostic view and the cognitive behavioral theory. In: Fairburn, CG., editor. Cognitive behavior therapy and eating disorders. Guilford Press; New York: 2008. p. 7-22.

Fairburn CG, Beglin SJ. Assessment of eating disorders: Interview or self-report questionnaire? International Journal of Eating Disorders 1994;16:363-370. [PubMed: 7866415]

Fairburn, CG.; Cooper, Z. The Eating Disorder Examination. In: Fairburn, CG.; Wilson, GT., editors. Binge eating: Nature, assessment, and treatment. 12th edition. Guilford Press; New York: 1993. p. 317-360.

Federici A, Kaplan AS. The patient's account of relapse and recovery in anorexia nervosa: A qualitative study. European Eating Disorders Review 2008;16:1-10. [PubMed: 18074326]

Fichter MM, Quadflieg N, Hedlund S. Twelve-year course and outcome predictors of anorexia nervosa. International Journal of Eating Disorders 2006;39:87-100. [PubMed: 16231345]

Field AE, Herzog DB, Keller MB, West J, Nussbaum K, Colditz GA. Distinguishing recovery from remission in a cohort of bulimic women: How should asymptomatic periods be described? Journal of Clinical Epidemiology 1997;50:1339-1345. [PubMed: 9449937]

First, MB.; Spitzer, RL.; Gibbon, M.; Williams, JB. Structured Clinical Interview for the DSM-IV Axis I disorders - Patient edition (SCID-I/P, version 2). New York State Psychiatric Institute, Biometrics Research Department; New York: 1995.

Frank E. Describing course of illness: Does our language matter? International Journal of Eating Disorders 2005;38:7-8. [PubMed: 15971234]

Frank E, Prien RF, Jarrett RB, Keller MB, Kupfer DJ, Lavori PW, et al. Conceptualization and rationale for consensus definitions of terms in major depressive disorder: Remission, recovery, relapse, and recurrence. Archives of General Psychiatry 1991;48:851-855. [PubMed: 1929776]

Garner DM, Olmsted MP, Bohr Y, Garfinkel PE. The Eating Attitudes Test: Psychometric features and clinical correlates. Psychological Medicine 1982;12:871-878. [PubMed: 6961471]

Grilo CM, Masheb RM, Wilson GT. A comparison of different methods for assessing the features of eating disorders in patients with binge eating disorder. Journal of Consulting and Clinical Psychology 2001;69:317-322. [PubMed: 11393608] 
Halvorsen I, Andersen A, Heyerdahl S. Good outcome of adolescent onset anorexia nervosa after systematic treatment: Intermediate to long-term follow-up of a representative county-sample. European Child \& Adolescent Psychiatry 2004;13:295-306. [PubMed: 15490277]

Herpertz-Dahlmann B, Muller B, Herpertz S, Heussen N, Hebebrand J, Remschmidt H. Prospective 10year follow-up in adolescent anorexia nervosa: Course, outcome, psychiatric comorbidity, and psychosocial adaptation. Journal of Child Psychology and Psychiatry 2001;42:603-612. [PubMed: 11464965]

Herzog DB, Dorer DJ, Keel PK, Selwyn SE, Ekeblad ER, Flores AT, et al. Recovery and relapse in anorexia and bulimia nervosa: A 7.5-year follow-up study. Journal of the American Academy of Child \& Adolescent Psychiatry 1999;38:829-837. [PubMed: 10405500]

Herzog DB, Sacks NR, Keller MB, Lavori PW, von Ranson KB, Gray HM. Patterns and predictors of recovery in anorexia nervosa and bulimia nervosa. Journal of the American Academy of Child and Adolescent Psychiatry 1993;32:835-842. [PubMed: 8340307]

Herzog W, Schellberg D, Deter H. First recovery in anorexia nervosa patients in the long-term course: A discrete-time survival analysis. Journal of Counseling and Clinical Psychology 1997;65:169-177.

Hohlstein LA, Smith GT, Atlas JG. An application of expectancy theory to eating disorders: Development and validation of measures of eating and dieting expectancies. Psychological Assessment 1998;10:49-58.

Kaye WH, Bulik CM, Thornton L, Barbarich N, Masters K, Price Foundation Collaborative Group. Comorbidity of anxiety disorders with anorexia and bulimia nervosa. American Journal of Psychiatry 2004;161:2215-2221. [PubMed: 15569892]

Keel PK, Dorer DJ, Franko DL, Jackson SC, Herzog DB. Postremission predictors of relapse in women with eating disorders. American Journal of Psychiatry 2005;162:2263-2268. [PubMed: 16330589]

Keel PK, Mitchell JE, Miller KB, Davis TL, Crow SJ. Social adjustment over 10 years following diagnosis with bulimia nervosa. International Journal of Eating Disorders 2000;27:21-28. [PubMed: 10590445]

Keski-Rahkonen A, Hoek HW, Linna MS, Raevuori A, Sihvola E, Bulik CM, et al. Incidence and outcomes of bulimia nervosa: A nationwide population-based study. Psychological Medicine 2009;39:823-831. [PubMed: 18775085]

Keski-Rahkonen A, Tozzi F. The process of recovery in eating disorder sufferers' own words: An Internetbased study. International Journal of Eating Disorders 2005;37(Suppl):S80-S86. [PubMed: 15852327]

Klump KL, Strober M, Bulik CM, Thornton L, Johnson C, Devlin B, et al. Personality characteristics of women before and after recovery from an eating disorder. Psychological Medicine 2004;34:14071418. [PubMed: 15724872]

Kordy H, Kramer B, Palmer RL, Papezova H, Pellet J, Richard M, et al. Remission, recovery, relapse, and recurrence in eating disorders: Conceptualization and illustration of a validation strategy. Journal of Clinical Psychology 2002;58:833-846. [PubMed: 12205723]

Lowe B, Zipfel S, Buchholz C, Dupont Y, Reas DL, Herzog W. Long-term outcome of anorexia nervosa in a prospective 21-year follow-up study. Psychological Medicine 2001;31:881-890. [PubMed: 11459385]

Luce KH, Crowther JH. The reliability of the Eating Disorder Examination - Self-report questionnaire version (EDE-Q). International Journal of Eating Disorders 1999;25:349-351. [PubMed: 10192002]

Matsunaga H, Kaye WK, McConaha C, Plotnicov K, Pollice C, Rao R. Personality disorders among subjects recovered from eating disorders. International Journal of Eating Disorders 2000;27:353357. [PubMed: 10694723]

McKinley NM, Hyde JS. The objectified body consciousness scale: Development and validation. Psychology of Women Quarterly 1996;20:181-215.

Mizes JS, Christiano B, Madison J, Post G, Seime R, Varnado P. Development of the Mizes Anorectic Cognitions Questionnaire - Revised: Psychometric properties and factor structure in a large sample of eating disorder patients. International Journal of Eating Disorders 2000;28:415-421. [PubMed: 11054788]

Mond JM, Hay PJ, Rodgers B, Owen C. Eating Disorder Examination Questionnaire (EDE-Q): Norms for young adult women. Behaviour Research and Therapy 2006;44:53-62. [PubMed: 16301014] 
Morgan HG, Russell GF. Value of family background and clinical features as predictors of long-term outcome in anorexia nervosa: A 4-year follow-up study of 41 patients. Psychological Medicine 1975;5:355-371. [PubMed: 1197538]

Noordenbos G, Seubring A. Criteria for recovery from eating disorders according to patients and therapists. Eating Disorders 2006;14:41-54. [PubMed: 16757448]

Pike KM. Long-term course of anorexia nervosa: Response, relapse, remission, and recovery. Clinical Psychology Review 1998;18:447-475. [PubMed: 9638357]

Pollice C, Kaye WH, Greeno CG, Weltzin TE. Relationship of depression, anxiety, and obsessionality to state of illness in anorexia nervosa. International Journal of Eating Disorders 1997;21:367-376. [PubMed: 9138049]

Quadflieg N, Fichter MM. The course and outcome of bulimia nervosa. European Child and Adolescent Psychiatry 2003;12:99-109.

Reas DL, Williamson DA, Martin CK, Zucker NL. Duration of illness predicts outcome for bulimia nervosa: A long-term follow-up study. International Journal of Eating Disorders 2000;27:428-434. [PubMed: 10744849]

Roberto CA, Steinglass J, Mayer LES, Attia E, Walsh BT. The clinical significance of amenorrhea as a diagnostic criterion of anorexia nervosa. International Journal of Eating Disorders 2008;41:559-563. [PubMed: 18454485]

Rush AJ, Kraemer HC, Sackeim HA, Fava M, Trivedi MH, Frank E, et al. Report by the ACNP Task Force on response and remission in major depressive disorder. Neuropsychopharmacology 2006;31:1841-1853. [PubMed: 16794566]

Steinhausen H-C. The outcome of anorexia nervosa in the $20^{\text {th }}$ century. The American Journal of Psychiatry 2002;159:1284-1293. [PubMed: 12153817]

Striegel-Moore RH, Seeley JR, Lewinsohn PM. Psychosocial adjustment in young adulthood of women who experienced an eating disorder during adolescence. Journal of the American Academy of Child and Adolescent Psychiatry 2003;42:587-593. [PubMed: 12707563]

Strober M, Freeman R, Morrell W. The long-term course of severe anorexia nervosa in adolescents: Survival analysis of recovery, relapse, and outcome predictors over 10-15 years in a prospective study. International Journal of Eating Disorders 1997;22:339-360. [PubMed: 9356884]

Thompson JK, van den Berg P, Roehrig M, Guarda AS, Heinberg LJ. The Sociocultural Attitudes Towards Appearance Scale-3 (SATAQ-3): Development and validation. International Journal of Eating Disorders 2004;35:293-304. [PubMed: 15048945]

Tozzi F, Thornton LM, Klump KL, Fichter MM, Halmi KA, Kaplan AS, et al. Symptom fluctuation in eating disorders: Correlates of diagnostic crossover. American Journal of Psychiatry 2005;162:732740. [PubMed: 15800146]

Von Holle A, Pinheiro AP, Thornton LM, Klump KL, Berrettini WH, Brandt H, et al. Temporal patterns of recovery across eating disorder subtypes. Australian and New Zealand Journal of Psychiatry 2008;42:108-117. [PubMed: 18197505]

Wagner A, Barbarich-Marsteller NC, Frank GK, Bailer UF, Wonderlich SA, Crosby RC, et al. Personality traits after recovery from eating disorders: Do subtypes differ? International Journal of Eating Disorders 2006;39:276-284. [PubMed: 16528697]

Walsh BT. Recovery from eating disorders. Australian and New Zealand Journal of Psychiatry 2008;42:95-96. [PubMed: 18197503]

Wentz E, Gillberg C, Gillberg IC, Rastam M. Ten-year follow-up of adolescent-onset anorexia nervosa: Psychiatric disorders and overall functioning scales. Journal of Child Psychology and Psychiatry 2001;42:613-622. [PubMed: 11464966]

Yackobovitch-Gavan M, Golan M, Valevski A, Kreitler S, Bachar E, Lieblich A, et al. An integrative quantitative model of factors influencing the course of anorexia nervosa over time. International Journal of Eating Disorders 2009;42:306-317. [PubMed: 19040269] 


\section{Table 1}

Description of published measures used for testing the validity of the eating disorder status groups

\begin{tabular}{ll}
\hline Measure & Description \\
\hline $\begin{array}{l}\text { Eating Attitudes Test-26 (EAT-26) } \\
\text { (Garner, Olmsted, Bohr, \& Garfinkel, 1982) }\end{array}$ & Assesses anorexic behaviors and cognitions \\
$\begin{array}{l}\text { Mize Anorectic Cognitions Test-Revised (MAC-R) } \\
\text { (Mizes, Christiano, Madison, Post, Seime, \& Varnado, 2000) }\end{array}$ & $\begin{array}{l}\text { Assesses eating disorder cognitions related to } \\
\text { weight, food, and } \\
\text { eating }\end{array}$ \\
$\begin{array}{l}\text { Body Shame subscale of the Objectified Body Consciousness } \\
\begin{array}{l}\text { Scale (OBCS) } \\
\text { (McKinley \& Hyde, 1996) }\end{array}\end{array}$ & $\begin{array}{l}\text { Assesses the degree to which an individual feels } \\
\text { like a bad person } \\
\text { if she isn't fulfilling cultural expectations } \\
\text { regarding the body }\end{array}$ \\
$\begin{array}{l}\text { Appearance Schemas Inventory-Revised (ASI-R) } \\
\text { (Cash, Melnyk, \& Hrabosky, 2004) }\end{array}$ & $\begin{array}{l}\text { Assesses individuals' psychological investment } \\
\text { in their physical } \\
\text { appearance }\end{array}$ \\
$\begin{array}{l}\text { Thinness and Restricting Expectancy Inventory (TREI) } \\
\text { (Hohlstein, Smith, \& Atlas, 1998) }\end{array}$ & $\begin{array}{l}\text { Assesses broad expectations for overgeneralized } \\
\text { life improvement } \\
\text { due to dieting and thinness }\end{array}$ \\
$\begin{array}{l}\text { General Internalization subscale of the Sociocultural Attitudes } \\
\text { Toward Appearance Questionnaire (SATAQ-3) } \\
\text { (Thompson, van den Berg, Roehrig, Guadra, \& Heinberg, 2004) }\end{array}$ & $\begin{array}{l}\text { Assess the degree to which individuals "buy } \\
\text { into" the thin-ideal } \\
\text { presented in the media as being important and } \\
\text { goal-worthy }\end{array}$ \\
\hline
\end{tabular}


Table 2

Descriptive statistics

\begin{tabular}{lllll}
\hline & $\begin{array}{l}\text { Active ED } \\
(\boldsymbol{n}=\mathbf{5 3})\end{array}$ & $\begin{array}{l}\text { Partially Recovered } \\
\text { ED } \\
(\boldsymbol{n = 1 5})\end{array}$ & $\begin{array}{l}\text { Fully Recovered ED } \\
(\boldsymbol{n = 2 0})\end{array}$ & $\begin{array}{l}\text { Healthy Controls } \\
(\boldsymbol{n}=\mathbf{6 7})\end{array}$ \\
\hline Age & 23.18 years (4.39) & 23.53 years (5.80) & 24.55 years (4.89) & 19.46 years (1.88) \\
Ethnicity & $92.5 \%$ Caucasian & $93.3 \%$ Caucasian & $95.0 \%$ Caucasian & $89.6 \%$ Caucasian \\
Socio-economic status & 16.68 years (2.79) & 16.63 years (2.52) & 16.60 years (3.14) & 16.52 years (2.65) \\
\hline
\end{tabular}

Note: $\mathrm{ED}=$ eating disorder. Means and standard deviations are reported for age and socio-economic status, with socio-economic status reflecting parents' highest level of education attained. 


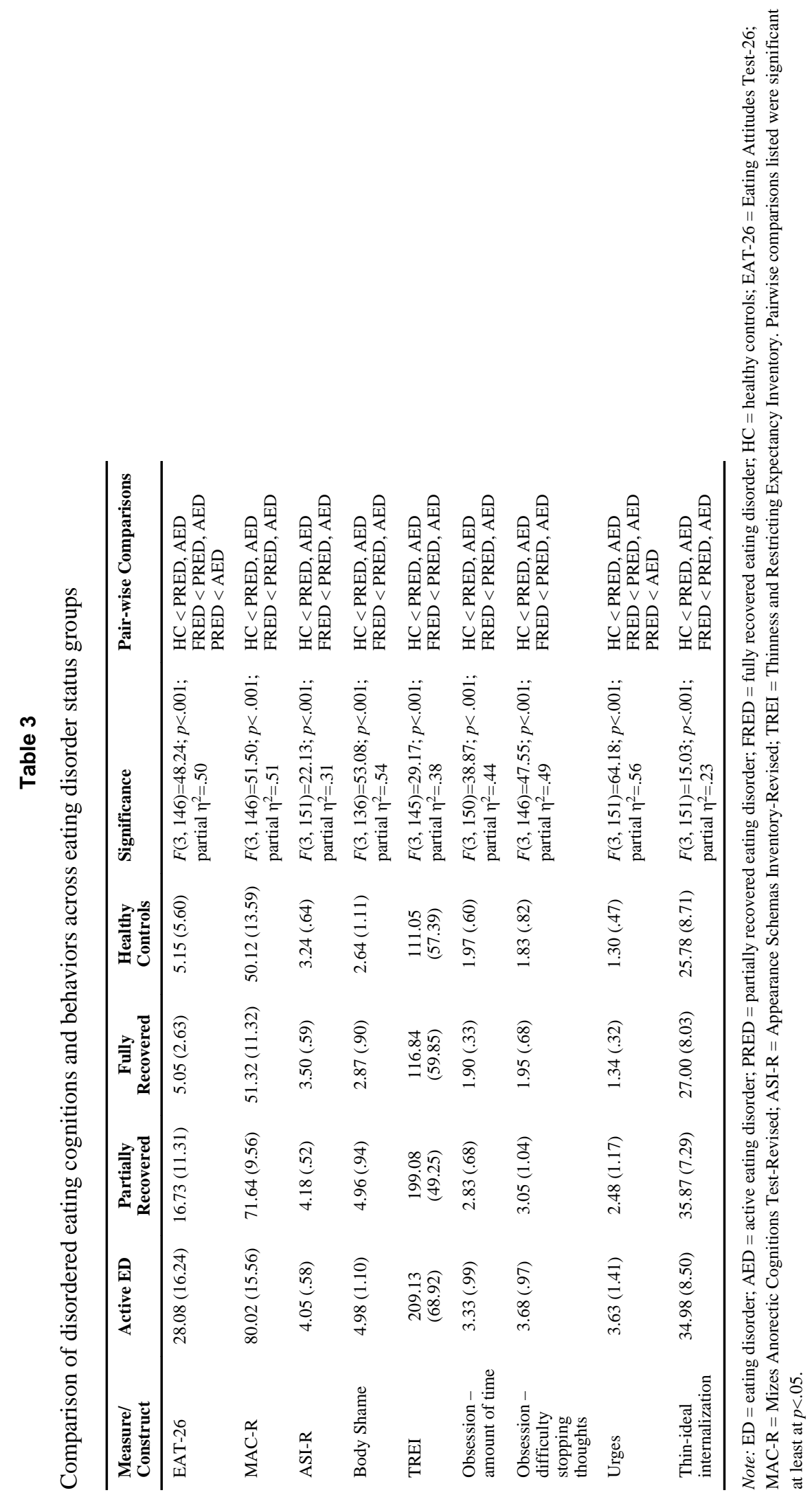




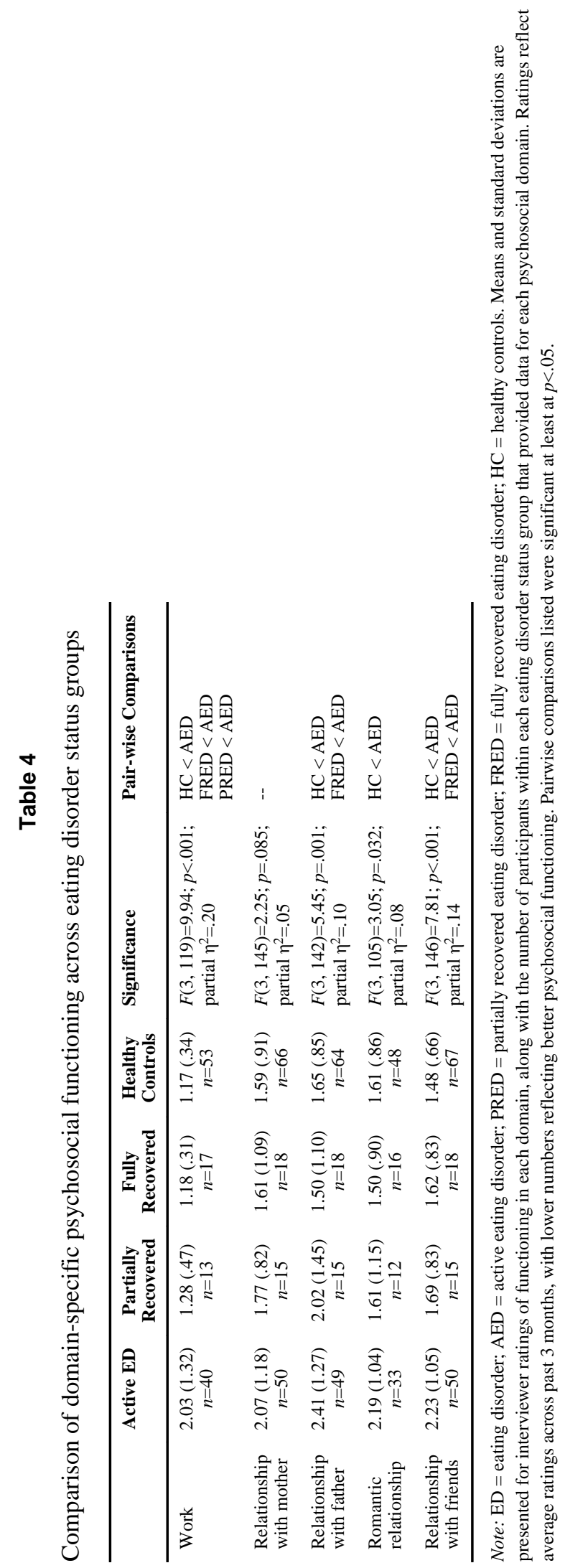

Behav Res Ther. Author manuscript; available in PMC 2011 March 1. 


\section{Table 5}

Comparison of presence of eating disorder interference in specific psychosocial domains across eating disorder status groups

\begin{tabular}{lcccl}
\hline & Active ED & Partially Recovered & Fully Recovered & Significance \\
\hline Work & $23.7 \%$ & $7.7 \%$ & $0 \%$ & Fisher's exact test=5.50, $p=.054$ \\
$\begin{array}{l}\text { Relationship with } \\
\text { Mother }\end{array}$ & $34.7 \%$ & $13.3 \%$ & $5.9 \%$ & Fisher's exact test $=6.66, p=.038$ \\
$\begin{array}{l}\text { Relationship with } \\
\text { Father }\end{array}$ & $35.4 \%$ & $6.7 \%$ & $0 \%$ & Fisher's exact test=12.04, $p=.002$ \\
$\begin{array}{l}\text { Romantic } \\
\text { Relationship }\end{array}$ & $69.7 \%$ & $33.3 \%$ & $14.3 \%$ & $\chi^{2}(2, N=59)=13.58, p=.001$ \\
$\begin{array}{l}\text { Relationships with } \\
\text { Friends }\end{array}$ & $39.5 \%$ & $6.7 \%$ & $5.9 \%$ & Fisher's exact test=10.45, $p=.004$ \\
\hline
\end{tabular}

Note: ED = eating disorder. Fisher's exact tests are reported in cases when one or more cells had an expected count less than 5. Percentiles represent the percentages who reported having eating disorder aspects interfere with their functioning in the various psychosocial domains in the past 3 months. 


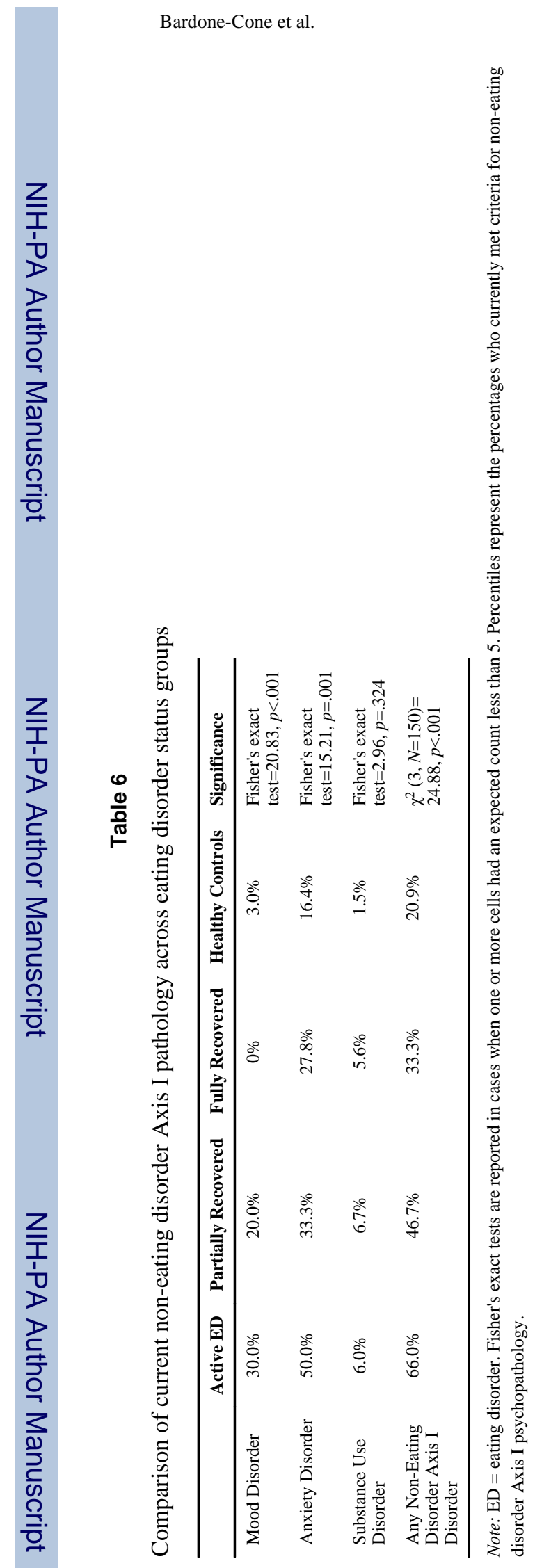

Behav Res Ther. Author manuscript; available in PMC 2011 March 1. 